\title{
ROLE OF PHENYTOIN IN THE MANAGEMENT OF NEUROGENIC CANCER PAIN
}

\author{
MQ Baig ${ }^{1}$, R Hadi $^{2}$, A Singhal ${ }^{3}$, SKS Gautam ${ }^{4}$ \\ ${ }^{1}$ Department of Radiation Oncology, BRD Medical College, Gorakhpur, Uttar Pradesh, India \\ ${ }^{2}$ Department of Radiation Oncology, ${ }^{3}$ Department of Surgical Oncology, ${ }^{4}$ Department of Anesthesiology \\ ,Dr Ram Manohar Lohia Institute of Medical Sciences, Lucknow, Uttar Pradesh, India
}

*Corresponding author:drrahathadi@yahoo.co.in,drrahathadi@gmail.com

Key words: Neurogenic pain, Cancer, Phenytoin

\begin{abstract}
Anticonvulsants are a group of medicines commonly used for treating 'fits' or epilepsy, but are also effective for pain. The type of pain which responds well is neurogenic (neuropathic) pain. Although anticonvulsants are used widely in chronic pain, as it is less effective in acute pain, surprisingly few studies (consists of case reports and open studies) showed analgesic effectiveness in cancer pain. Neurogenic pain is often very resistant to treatment. Tricyclic antidepressants, anticonvulsants, membrane stabilizers and capsaicin can relieve neurogenic pain in different proportions. Anticonvulsants have differing modes of action and therefore failure to respond to one, does not imply that others may not work. There is a need for further controlled studies of anticonvulsants in both peripheral and central neurogenic pain. We are presenting a case report of soft tissue sarcoma of right scapular region that giving rise to neurogenic pain which was relieved with Phenytoin after trying multiple medications.
\end{abstract}

Tissue injury is usually accompanied by pain and is described as neurogenic if the initiating injury occurs to neural tissue either centrally or peripherally. Typical features of neurogenic pain, regardless of the causal injury, include shooting, lancinating pain, burning pain, paraesthesia, dysaesthesia, numbness and allodynia. ${ }^{1}$

The clinical syndromes representing this type of disorder make up at least $25 \%$ of the patients attending most pain clinics and are much commoner than generally recognized. ${ }^{2}$

Many drugs have been tried from antiinflammatory, analgesics, antidepressant, antipsychotics, membrane stabilizers, capsaicin and anticonvulsants with variable results

\section{Case Report}

A 15 year old female was referred to the department of Radiotherapy (RT), with an inoperable soft tissue sarcoma of the right scapular region. Flowing clinical assessment, hematological investigations and radiological assessment, it neoadjuvant chemotherapy (NACT) Vincristine, Adriamycin, and Cyclophosphamide (VAC) regimen (3 weekly) followed by reassessment for any surgical intervention, after 3 cycles. Patient was started on the above mentioned regimen as an indoor patient with Vincristine 1.5 $\mathrm{mg} / \mathrm{m} 2$, Adriamycin $50 \mathrm{mg} / \mathrm{m} 2$ and Cyclophosphamide $500 \mathrm{mg} / \mathrm{m} 2$ intravenously.

On the 5th day following of her discharge in stable condition, patient arrived in the Out Patient Department (OPD) with severe jaw pain. She was admitted and started on the routine pain killers, but due to suboptimal response Carbamazapine $100 \mathrm{mg}$ three times a day (TDS) was added. After 2 days, pain was relieved and she was discharged with advice to come back on due date for 2 nd cycle of chemotherapy. 
Due to pain in the $1^{\text {st }}$ cycle chemotherapy, the Vincristine dose was reduced to $1 \mathrm{mg}$ this time, but again on $5^{\text {th }}$ day of completion of her 2nd cycle, she came in to the OPD with severe disabling pain in the cervical region radiating to the scalp. X-ray of the cervical region was normal. Injection (Inj) Tramadol $50 \mathrm{mg}$ IntraMuscular (IM) twice daily was started but due to inadequate relief, Inj Voveran $50 \mathrm{mg}$ IM BD was given along with tablet (tab) Carbamazapine $200 \mathrm{mg}$ per-orally tds. Due to non- relief of pain, on 3rd day, she was given tab Gabapentin $300 \mathrm{mg}$.... tds with no relief. On 4th day she was put on Inj Dexamethasone $8 \mathrm{mg}$ Intravenous (IV) TDS and Inj Epsoline (Dilantin Sodium) 100mg IV tds. She responded dramatically and her pain subsided completely within 3 days. She was discharged on tab Epsoline $100 \mathrm{mg} \&$ tab Dexamethasone $4 \mathrm{mg}$ tds for 4 days and after that, rest of the period was uneventful.

When she came for the $3^{\text {rd }}$ cycle, she was having $60 \%$ objective response, Response Evaluation Criteria In Solid Tumors (RECIST), at primary site without any neurogenic pain. However, it was planned to withhold VAC regime and was switched over to ICE (Ifosfamide, Carboplatin and Etoposide) regimen due to intolerance of the first regime.

\section{Discussion}

We commonly encounter neurogenic pain while managing cancer. Vincristine is one of the commonest chemotherapeutic agents which cause peripheral neuropathy and sometimes severe neurogenic pain.

Neuropathic pain responds inconsistently to opioids and nonsteroidal anti-inflammatory drugs. However, oral anticonvulsants have a proven analgesic effect on neuropathic pain. The first report of an anticonvulsant drug relieving neuropathic pain was that of Bergouignan ${ }^{3}$ in 1942 with phenytoin. Since that time, there have been few randomized, controlled trials of the analgesic effect of this drug in neuropathic pain. ${ }^{4,5}$

The effect of phenytoin may be its membrane stabilizing effect, an effect it shares with lignocaine and mexiletine. With chronic, stable neuropathic pain, oral anticonvulsant drugs can be titrated to an effective dose. Yajnik et al ${ }^{6}$ have reported $>50 \%$ pain relief in $72 \%$ patients with a phenytoin dose of $100 \mathrm{mg}$ BD for 1 month duration in a randomized double blind study. In this case we have used a higher dose of phenytoin looking at the severe nature of pain and favorable side effect profile of the drug.

To conclude, the present case report supports the use of oral phenytoin in neuropathic pain, with minimal side effects.

\section{References:}

1. McCleane G. The Pharmacological Management of Neuropathic Pain: A Review.

2. Bowsher D. Neurogenic pain syndromes and their management. British Medical Bulletin .1991; 47:644-666.

3. Bergouignan M. Cures heureuses de nevralgies faciales essentielles par le diphenylhydantoinate de soude. Rev Laryngol Otol Rhinol 1942; 63: 34 - 41.

4. Chadda VS, Mathur MS. Double blind study of the effects of diphenylhydantoin sodium on diabetic neuropathy. J Assoc Physicians India 1978;26:403-6

5. Saudek CD, Werns S, Reidenberg MM. Phenytoin in the treatment of diabetic symmetrical polyneuropathy. Clin Pharmacol Ther 1977; 22:196-9.

6. Yajnik S, Singh GP, Singh G, Kumar M. Phenytoin as a co-analgesic in cancer pain. $J$ Pain Symptom Manage. 1992; 7:209-13.

7. Trousseau A. De la nevralgie Epileptiforme. Clin Med Hotel Dieu 1885; 2: 33 - 44.

8. McQuay H, Carroll D, Jadad AR, Wiffen P, Moore A. Anticonvulsant drugs for management of pain: a systematic review. BMJ 1995; 311: 1047 - 52.

9. Kingery WS. A critical review of controlled trials for peripheral neuropathic pain and complex regional pain syndrome. Pain 1997; 73: 123 - 39 . 